\title{
What are kids vaping? Results from a national survey of US adolescents
}

\author{
Richard Miech, Megan E Patrick, Patrick M O'Malley, Lloyd D Johnston
}

- Additional material is published online only. To view please visit the journal online (http://dx.doi.org/10.1136/ tobaccocontrol-2016-053014).

Institute for Social Research, University of Michigan, Ann Arbor, Michigan, USA

\section{Correspondence to} Dr Richard Miech, Institute for Social Research, University of Michigan, 426 Thompson, Ann Arbor, MI 48104, USA; ramiech@umich.edu

Received 25 February 2016 Revised 16 May 2016 Accepted 24 May 2016 Published Online First 21 July 2016

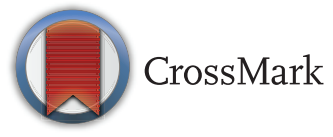

To cite: Miech $\mathrm{R}$, Patrick ME, O'Malley PM, et al. Tob Control

2017:26:386-391.

\section{ABSTRACT}

Objective To examine what substances US youth vape. Methods Data come from Monitoring the Future, an annual, nationally representative survey of USA 12th-grade, 10th-grade and 8th-grade students. Respondents reported what substance they vaped the last time they used a vaporiser such as an e-cigarette. Results Among students who had ever used a vaporiser, $65-66 \%$ last used 'just flavouring' in 12 th, in 10 th and in 8th grade, more than all other responses combined. In all three grades, the percentage using 'just flavouring' was above $57 \%$ for males, females, AfricanAmericans, Hispanics, Whites, and students both with and without a parent with a college degree. Nicotine use came in a distant second, at about $20 \%$ in 12 th and 10 th grade and $13 \%$ in 8 th grade. Taking into account youth who vaped nicotine at last use increases national estimates of tobacco/nicotine prevalence in the past 30 days by $24-38 \%$ above and beyond cigarette smoking, which is substantial but far less than estimates that assume all vaporiser users inhale nicotine.

Conclusions These results challenge the common assumption that all vaporiser users inhale nicotine. They (a) call into question the designation of vaporisers and e-cigarettes as ENDS ('Electronic Nicotine Delivery System'), (b) suggest that the recent rise in adolescent vaporiser use does not necessarily indicate a nicotine epidemic, and (c) indicate that vaporiser users can be candidates for primary prevention programmes. Finally, the results suggest the importance of developing different rationales for the regulation of vaporiser devices as compared to the regulation of substances marketed for vaporiser use.

\section{INTRODUCTION}

Adolescents' use of vaporisers such as e-cigarettes has increased rapidly in recent years in the USA. In 2015, 30-day prevalence of e-cigarettes was $16 \%$ among 12 th graders, $14 \%$ among 10 th graders and $10 \%$ among 8 th graders. ${ }^{1}$ This is a rapid growth from a 30 -day prevalence of near $1 \%$ among secondary school students in $2011 .^{2}$ The use has grown to such an extent that among adolescents 30-day prevalence of e-cigarette use in 2015 was higher than prevalence of any tobacco product, including traditional tobacco cigarettes. ${ }^{13} \mathrm{~A}$ common assumption among researchers and policymakers is that adolescents are vaping nicotine, although this assumption has yet to be examined closely.

This study presents some of the first information on the substances that US youth are vaping. We present results from the 2015 Monitoring the Future study (MTF), which asked students whether they vaped nicotine, marijuana, just flavouring, some other substance, or whether they did not know what they vaped. MTF is a large, nationally representative study of US 8th-, 10th-, and 12th-grade students in the 48 contiguous states. ${ }^{4}$

The term 'vaporiser' refers to battery-powered devices with a heating element and is a term that includes the specific vaporiser device of e-cigarettes. Vaporisers produce an aerosol, small particulates suspended in air and vapour, the gas phase of chemicals, that users inhale. The liquid that is used in vaporisers comes in hundreds of flavours, which are available both with and without nicotine per the user's choice.

The extent to which youth vape nicotine is not currently known. On the one hand, a common assumption in the field is that nicotine is the predominant substance that youth vape. This assumption is implicit in the name 'ENDS', the term often used for vaporisers in academic and government reports. This acronym stands for 'Electronic Nicotine Delivery Systems', a name that implies all users are inhaling nicotine. The term 'e-cigarette' that is widely used in the research and popular literatures also implies nicotine use. Furthermore, this assumption of nicotine vaping underlies the practice of categorising all vaporiser users as tobacco/nicotine users, a practice used in US national estimates of tobacco use. ${ }^{5}$

On the other hand, it is possible that a large percentage of youth who use vaporisers do not vape nicotine. For example, $70 \%$ of Canadian high school students who had ever used an e-cigarette had never vaped nicotine, ${ }^{6}$ a finding replicated among the general adult Canadian population. ${ }^{7}$ It is important to note that the generalisability of this finding to countries other than Canada is not certain; Canada's regulatory context is unique because e-cigarettes with nicotine are technically not legal, ${ }^{7}$ which may lower the prevalence of nicotine vaping.

Identifying the percentage of US adolescents who use vaporisers to inhale nicotine contributes to the literature in at least two ways. First, this information is important for the interpretation of the recent, exponential increase in e-cigarette use among US adolescents. Whether or not the increase should be interpreted as an epidemic of adolescent nicotine use is contingent on the percentage of youth who are using vaporisers to inhale nicotine. Second, the percentage who vape nicotine has important implications for regulation. A percentage substantially $<100 \%$ underscores the need to consider the difference between regulating vaporiser devices as compared to regulating the substances that are vaped.

\section{METHODS \\ Data}

Data come from the annual Monitoring the Future study, which since 1975 has used questionnaires 
administered in classrooms to survey nationally representative samples of students in the 48 contiguous US states. ${ }^{4}$ The survey consists of three separate, nationally representative samples of 12th-grade, 10th-grade and 8th-grade students and this analysis uses data from the year 2015, the first year that the survey asked respondents what substances they vaped. Data collection was approved by the University of Michigan Institutional Review Board. Students were informed that their answers in the aggregate would be used to produce national estimates, that their answers would be confidential, that participation was completely voluntary and that they should leave blank any question they did not wish to answer.

In 2015, a total of 44892 students located in 382 public and private schools participated, with student response rates of $89 \%, 87 \%$ and $83 \%$ in 8 th, 10 th and 12 th grades, respectively. The great majority of non-response is due to student absence. Schools are selected using a multistage, stratified research design. ${ }^{8}$ The first stage is the geographic area and consists of 164 primary areas. The second stage is schools, and response rates of originally selected schools were $41 \%$ in 8 th grade, $52 \%$ in 10th grade and $48 \%$ in 12th grade. For schools that do not participate, replacements are chosen to be as similar as possible to the original school being replaced in terms of region, demographics and population density; 93\% of sample slots were filled with an original or replacement. Given that most variation in substance use is within schools and not across them-only about $4-5 \%$ of the variation in 30 -day marijuana use is between schools ${ }^{9}$-any bias introduced by replacement schools is expected to be small.

Questions about vaping were asked of a randomly selected one-third of the samples in 12th grade $(\mathrm{n}=4591), 10$ th grade $(\mathrm{n}=5379)$ and 8 th grade $(\mathrm{n}=5013)$. In 2015, respondents were asked whether they ever used a vaporiser with the question "Electronic vaporizers make a mist that is inhaled and have the feel of cigarette smoking. Examples include e-cigarettes and e-pens. Have you ever used an electronic vaporizer such as an ecigarette?" Respondents who had ever used a vaporiser were asked "The LAST TIME you used an electronic vaporizer such as an e-cigarette, what was in the mist you inhaled?" to which respondents chose one reply from the choices 'Nicotine,' 'Marijuana or hash oil,' 'Just flavouring,' 'Other,' and 'Don't know.' Respondents who had ever used a vaporiser were also asked the frequency of use in the past 30 days, with responses of $0,1-5$ days and $>5$ days. Respondents were also asked whether they had smoked a regular cigarette in the past 30 days. The survey included self-reported sociodemographic information on gender, parental education and race/ethnicity, the latter of which identified the categories of non-Hispanic White, non-Hispanic Black and Hispanic respondents. For 12th-grade students, the survey also included questions on e-cigarettes, in particular. Students were asked "During the LAST 30 DAYS (if any), have you used electronic cigarettes (e-cigarettes)?"

The analyses are based on all data available for univariate and bivariate distributions (tables 1-3) and use listwise deletion for comparison of different ways to estimate tobacco/nicotine prevalence (table 4). All analyses use weights and were performed with Stata MP V.12.1 software (StataCorp. Stata Statistical Software: Release 12.0. College Station, Texas, USA: StataCorp LP; 2011). We use the STATA 'survey' algorithms to take into account clustering within strata and schools for the calculation of SEs.

Analysis of missing data indicated that it had little influence on the results of this study. Completion rates for the question on lifetime vaporiser use were $90 \%, 94 \%$ and $91 \%$ in 12 th, 10th and 8th grade, respectively. To consider the potential influence of missing data on the distribution of substance vaped, we ran an imputed data analysis, which generated 20 datasets that assigned values to missing data on the basis of responses to other survey questions, including cigarette smoking. Of this study's 70 estimates for prevalence of different substances vaped (reported in table 2), none of the values from the imputed analysis differed by more than 1.07 percentage-points from the analysis based on the reported data only. Of the respondents who answered the question on lifetime vaporiser use, missing data values for demographic characteristics were $6 \%$ or less in all grades with the exception of parents' education as reported by 8 th-grade students, which was missing $13 \%$. Missing values on demographic variable did not significantly predict the type of substance vaped in any grade. We report results from analyses using non-imputed results for ease of interpretation.

\section{RESULTS}

Table 1 presents the sociodemographic distribution of the analysis samples. About half of respondents are female and slightly more than half have at least one parent who has a college degree. In terms of racial/ethnic composition, the majority of 8 th graders are members of minority racial/ethnic groups, while the $10^{\text {th }}$-grade and $12^{\text {th }}$-grade cohorts are majority White.

Table 2 presents the substances students vaped at last use, asked only of those who had ever vaped. 'Just flavouring' is by far the most commonly vaped substance. In all grades, for lifetime and past 30-day vaping subgroups, 'just flavouring' was vaped more than all other substances combined. Of the students who had ever used a vaporiser in their life (34\% of 12 th graders, $32 \%$ of 10 th graders and $21 \%$ of 8 th graders), $65-$ $66 \%$ in each grade reported vaping 'just flavouring' at last use. Of the students who had used a vaporiser in the past month (16\% of 12 th graders, $14 \%$ of 10 th graders and $8 \%$ of 8 th graders), $59-63 \%$ of students in each grade reported vaping 'just flavouring' at last use.

Vaping of nicotine came in a distant second place. Among respondents who had ever vaped, about $20 \%$ of 12 th and 10 th grade students and $13 \%$ of 8 th-grade students reported vaping nicotine at last use.

Vaping marijuana at last use was reported by about $6 \%$ of respondents who had ever vaped in their life in all three grades. Levels of marijuana vaping were higher among 10th-grade and 8 th-grade students who reported vaping in the past 30 days, with a prevalence of $9 \%$ and $11 \%$, respectively, but slightly lower among 12 th-grade students, $5 \%$.

Table 1 Sociodemographic characteristics of the samples by grade level (entries are percentages, and SEs are in parentheses)

\begin{tabular}{llll}
\hline Variable & $\begin{array}{l}\text { 12th } \\
\text { grade* }\end{array}$ & $\begin{array}{l}\text { 10th } \\
\text { gradet }\end{array}$ & 8th grade‡ \\
\hline Female & $52.09(1.13)$ & $49.38(0.93)$ & $51.40(0.75)$ \\
Non-Hispanic White & $52.88(3.21)$ & $56.60(2.90)$ & $45.78(3.12)$ \\
Hispanic & $16.73(2.66)$ & $15.86(2.07)$ & $23.66(2.66)$ \\
Non-Hispanic African-American & $15.13(2.27)$ & $10.05(1.57)$ & $14.24(1.83)$ \\
$\begin{array}{l}\text { At least one parent with college } \\
\text { degree }\end{array}$ & $52.95(2.33)$ & $60.85(2.37)$ & $56.39(2.07)$ \\
\hline
\end{tabular}

Percentages for race/ethnicity do not add to $100 \%$ because smaller groups are not presented.

${ }^{*} \mathrm{n}=4090$ to 4275 (unweighted).

$\mathrm{tn}=4898$ to 5219 (unweighted)

$\ddagger \mathrm{n}=4780$ to 4801 , with exception $\mathrm{n}=4251$ for parental education (unweighted) 
Table 2 Distribution of last substance vaped by frequency of vaporiser use and grade (estimates are percentages, and SEs are in parentheses)

\begin{tabular}{|c|c|c|c|c|}
\hline & \multirow[b]{2}{*}{ Any lifetime use of vaporiser } & \multicolumn{3}{|c|}{ Used vaporiser in past 30 days } \\
\hline & & Any use & $1-5$ times & $6+$ times \\
\hline \multicolumn{5}{|l|}{ Grade 12} \\
\hline Unweighted $\mathrm{n}$ & $n=1420$ & $n=625$ & $n=410$ & $n=215$ \\
\hline$\%$ of grade, weighted & $34.44(1.17)$ & $15.58(0.90)$ & $10.54(0.67)$ & $5.03(0.44)$ \\
\hline Just flavouring & $64.73(1.60)$ & $59.24(2.05)$ & $66.26(2.57)$ & $44.55(4.28)^{*}$ \\
\hline Nicotine & $22.16(1.49)$ & $30.72(2.26)$ & $22.73(2.78)$ & $47.48(4.49)^{*}$ \\
\hline Marijuana & $6.12(0.82)$ & $5.23(1.16)$ & $5.01(1.36)$ & $5.69(1.86)$ \\
\hline Don't know & $6.33(0.74)$ & $4.04(0.75)$ & $5.14(1.04)$ & $1.74(1.05)$ \\
\hline Other & $0.71(0.23)$ & $0.76(0.34)$ & $0.86(0.47)$ & $0.55(0.39)$ \\
\hline \multicolumn{5}{|l|}{ Grade 10} \\
\hline Unweighted $\mathrm{n}$ & $n=1649$ & $\mathrm{n}=704$ & $n=436$ & $n=268$ \\
\hline$\%$ of grade, weighted & $32.02(1.12)$ & $13.75(0.79)$ & $8.39(0.52) \dagger$ & $5.37(0.49)$ \\
\hline Just flavouring & $65.24(1.63)$ & $59.49(2.51)$ & $65.57(2.71)$ & $49.98(4.16)^{*}$ \\
\hline Nicotine & $19.87(1.30)$ & $27.39(2.30)$ & $18.98(2.28)$ & $40.53(4.23)^{*}$ \\
\hline Marijuana & $6.61(0.79)$ & $8.75(1.50)$ & $9.87(2.39)$ & $6.98(1.70)$ \\
\hline Don't know & $7.65(0.87)$ & $3.70(0.84)$ & $5.03(1.31)$ & $1.62(0.79)$ \\
\hline Other & $0.63(0.26)$ & $0.67(0.38)$ & $0.54(0.40)$ & $0.89(0.76)$ \\
\hline \multicolumn{5}{|l|}{ Grade 8} \\
\hline Unweighted $\mathrm{n}$ & $n=968$ & $\mathrm{n}=372$ & $\mathrm{n}=239$ & $n=133$ \\
\hline$\%$ of grade weighted & $21.07(0.94) \dagger \ddagger$ & $7.75(0.58) \dagger \ddagger$ & $5.08(0.35) \dagger \ddagger$ & $2.67(0.37) \dagger \ddagger$ \\
\hline Just flavouring & $65.96(2.05)$ & $62.66(3.05)$ & $64.26(3.75)$ & $59.61(5.37) \dagger$ \\
\hline Nicotine & $13.23(1.48) \dagger \ddagger$ & $16.23(2.51) \dagger \ddagger$ & $14.49(2.87)$ & $19.52(4.82) \dagger \ddagger$ \\
\hline Marijuana & $5.80(0.89)$ & $10.59(2.23) \dagger$ & $9.71(2.62)$ & $12.26(3.61)$ \\
\hline Don't know & $13.71(1.44) \dagger \ddagger$ & $7.88(1.25) \dagger \ddagger$ & $8.43(1.68)$ & $6.84(2.00) \dagger \ddagger$ \\
\hline Other & $1.30(0.46)$ & $2.65(1.16) \dagger$ & $3.11(1.67)$ & $1.77(0.99)$ \\
\hline
\end{tabular}

Only the categories in the last two columns are mutually exclusive.

*Significantly different from group that vaped $1-5$ times in past 30 days, $p<0.05$.

tSignificantly differs from the percentage in 12 th grade, $p<0.05$.

$\ddagger$ Significantly differs from the percentage in 10 th grade, $p<0.05$.

Respondents who vaped six or more times as compared to 1-5 times in the past 30 days showed significant differences in substances vaped in 12th and 10th grades. Specifically, in both grades, the respondents with higher frequency of vaping were significantly more likely to vape nicotine and significantly less likely to vape flavouring.

Table 3 presents the demographic distribution of substances last vaped among respondents who had ever used a vaporiser by 12 th grade. Nicotine was more likely to be vaped by males, by Whites and by respondents who had at least one parent with a college degree. Flavouring was more likely to be vaped by females and by Hispanics (compared to Whites).

In 10th and 8th grades, few comparisons across sociodemographic groups were significantly different and no strong pattern emerged (see online supplementary table S2). In 10th grade, only one out of 35 comparisons significantly differed. More significant differences are present among 8th-grade students, although these differences do not follow a clear pattern.

Table 4 presents two ways to incorporate vaporiser use into estimates of past 30-day tobacco/nicotine prevalence among

Table 3 Distribution of last substance vaped by demographic groups, among respondents in 12th grade who ever used a vaporiser (estimates are percentages, and SEs are in parentheses)

\begin{tabular}{|c|c|c|c|c|c|c|c|}
\hline & \multicolumn{2}{|l|}{ Sex } & \multicolumn{3}{|l|}{ Race/ethnicity } & \multicolumn{2}{|c|}{ Parental education } \\
\hline & Femalet & Male & $\begin{array}{l}\text { Non-hispanic } \\
\text { whitet }\end{array}$ & Hispanic & $\begin{array}{l}\text { Non-hispanic } \\
\text { African-American }\end{array}$ & $\begin{array}{l}\text { No parent has } \\
\text { college degreet }\end{array}$ & $\begin{array}{l}\text { Parent(s) with college } \\
\text { degree }\end{array}$ \\
\hline \multicolumn{8}{|l|}{ Variable } \\
\hline Unweighted $\mathrm{n}$ & 637 & 699 & 857 & 227 & 128 & 608 & 737 \\
\hline Just flavouring & $69.85(2.40)$ & $61.00^{*}(2.23)$ & $62.54(2.08)$ & $73.34^{*}(3.26)$ & $66.24(4.69)$ & $68.73(2.03)$ & $63.41(2.11)$ \\
\hline Nicotine & $17.53(2.04)$ & $26.29 *(2.26)$ & $25.89(1.83)$ & $15.59 *(2.80)$ & $11.42 *(4.29)$ & $17.17(1.74)$ & $25.22 *(2.18)$ \\
\hline Marijuana & $5.03(1.01)$ & $6.76(1.03)$ & $5.41(0.91)$ & $4.54(1.70)$ & $10.52(3.24)$ & $6.33(1.25)$ & $6.18(1.01)$ \\
\hline Don't know & $7.13(1.12)$ & $5.03(0.93)$ & $5.57(0.85)$ & $5.65(1.48)$ & $10.25(3.00)$ & $6.96(1.11)$ & $4.60(0.87)$ \\
\hline Other & $0.47(0.28)$ & $0.91(0.36)$ & $0.59(0.24)$ & $0.87(0.54)$ & $1.57(1.50)$ & $0.80(0.34)$ & $0.59(0.27)$ \\
\hline
\end{tabular}


Table 4 Estimates of nicotine prevalence in the past 30 days (SE are in parentheses)

\begin{tabular}{llll}
\hline & $\begin{array}{l}\text { 12th grade } \\
(\mathbf{n}=4039)\end{array}$ & $\begin{array}{l}\text { 10th grade } \\
(\mathbf{n}=5001)\end{array}$ & $\begin{array}{l}\mathbf{8} \text { th grade } \\
(\mathbf{n}=4506)\end{array}$ \\
\hline $\begin{array}{l}\text { Vaped any substance or } \\
\text { smoked regular cigarette(s) }\end{array}$ & $20.95(0.91)$ & $15.84(0.82)$ & $8.76(0.61)$ \\
$\begin{array}{l}\text { Vaped nicotine at last use or } \\
\text { smoked regular cigarette(s) }\end{array}$ & $12.44(0.71)$ & $7.88(0.55)$ & $3.96(0.36)$ \\
$\begin{array}{l}\text { Smoked regular cigarette(s) } \\
\text { 10.06 (0.63) }\end{array}$ & $5.71(0.45)$ & $3.23(0.34)$ \\
\hline
\end{tabular}

youth. One current approach is to consider all vaporiser users to be tobacco and nicotine users, regardless of what substance they are vaping. This approach doubles estimates of tobacco prevalence in 12th grade as compared to estimates based solely on cigarette smoking. In 10th and 8th grades, this approach almost triples the estimate of tobacco/nicotine prevalence. An alternative approach is to consider vaporisers to be tobacco/ nicotine users only if they reported nicotine as the last substance they vaped in the past 30 days, an approach that leads to much smaller increases in prevalence estimates; specifically, this approach increases tobacco/nicotine prevalence above and beyond cigarette use by $24 \%$ in 12 th grade $(1.24=12.44$ / 10.06 ), by $38 \%$ in 10 th grade and by $23 \%$ in 8 th grade.

Online supplementary tables S1 and S3 show that study results are similar when substituting e-cigarette use for vaporiser use. Online supplementary table S1 shows that the distribution of substances vaped among e-cigarette users is nearly identical to the results with vaporisers (compare with table 2). Online supplementary table S3 indicates that questions on 'e-cigarettes' produce similar tobacco/nicotine prevalence estimates as questions on 'vaporisers' (compare with table 4).

\section{DISCUSSION}

This study presents some of the first information on the substances that US adolescents vape. Nicotine is assumed by many to be the predominant substance that youth vape, although, to the best of our knowledge, this assumption is not based on the scientific data.

'Just flavouring'-and not nicotine-was by far the most commonly vaped substance in all grades. Among students who had ever used a vaporiser in their life, the portion who used 'just flavouring' the last time they vaped was greater than all other substances combined. This response was markedly consistent across grades and was reported by $65-66 \%$ of students in 12 th, in 10 th and in 8 th grades. In all grades, the percentage reporting that they had last vaped 'just flavouring' was above 57\% for males, females, Whites, Blacks, Hispanics, and students with and without a parent who had a college degree. The percentage who vaped 'just flavouring' at last use was also high among students who used a vaporiser in the past 30 days, at a prevalence of $59 \%$ or higher in all three grades.

Nicotine came in a distant second place among youth who had used a vaporiser. About $20 \%$ of 12 th and 10 th grade students and $13 \%$ of 8 th-grade students vaped nicotine at last use. Across the demographic groups of gender, race/ethnicity and parental education, nicotine use in vaporisers never exceeded $26 \%$ in any of the three grades. In 12th grade, its use was highest among Whites, males and students with at least one parent who had a college degree. This unusual pattern of greater use among more advantaged demographic groups is similar to the early diffusion of other substances such as cigarettes and cocaine, which had been concentrated in advantaged groups in past decades but are now concentrated in disadvantaged groups after the substances developed a reputation as dangerous. ${ }^{10-12}$

Among the group of students who had vaped in the past 30 days, the portion who last vaped nicotine was $31 \%$ in 12 th, $27 \%$ in 10 th and $16 \%$ in 8 th grade. Among students who had vaped $6+$ times in the past 30 days, these percentages were 25 $50 \%$ higher as compared to those who had vaped 1-5 times. This result indicates that the importance of the cut-off between vaping $1-5$ as compared to $6+$ times in the past 30 days-a threshold highlighted by previous research ${ }^{13}$ - extends to substances vaped. In no case did the prevalence of nicotine vaping reach $50 \%$ or greater.

We note that the percentage who vaped nicotine was higher in the older age groups; longitudinal data are required to determine whether this represents younger vapers progressing to nicotine and/or an influx of new vapers at older ages.

Levels of marijuana vaping were about $6 \%$ in each of the three grades among students who had ever used a vaporiser. These levels did not significantly differ by sociodemographic groups, with the exception in 8th grade of higher prevalence of marijuana vaping among Hispanics as compared to Whites. Among students who had used a vaporiser in the last 30 days, vaping of marijuana was highest in 8 th grade.

Some youth did not know what substance they last vaped. This percentage was $14 \%$ in 8 th grade and declined at older age groups, reaching $6 \%$ in 12 th grade. The lowest percentage was $2 \%$ among heavy vapers, who presumably are more intentional in the substances that they vape.

Four major implications follow from the study's main finding that most youth who use vaporisers do not use nicotine. First, these results suggest the need to reconsider the term 'ENDS' to denote vaporisers and e-cigarettes, at least among US adolescents. The term stands for 'electronic nicotine delivery system', which seems inaccurate for the description of a device that the majority of youth do not use to vape nicotine.

A second implication is the need to reconsider the impact of vaporisers on the estimated national prevalence of nicotine use among US youths. The current assumption that vaporiser use is synonymous with nicotine use leads to a doubling of past 30-day tobacco/nicotine prevalence in 12th grade and a near tripling in 10th and 8th grades (see tables 4 and S3) as compared to estimates based on cigarette use alone. However, the results from this study indicate that many vaporiser users do not vape nicotine. If vaporiser users are considered nicotine users only if they last vaped nicotine in the last 30 days, then national estimates of nicotine prevalence increase by a much smaller percentage of $23-38 \%$ across the three grades. These results indicate that while taking into account vaporiser use does indeed increase tobacco/nicotine prevalence, the impact of vaporisers is likely not as large as might appear by their recent, dramatic increase in use among adolescents.

A third implication is that vaporiser use may serve as an indicator for primary prevention programmes aimed at nicotine use. Because many US youth who use vaporisers do not vape nicotine, they are candidates for primary interventions, which are particularly strategic to combat nicotine use because they take place before the need to address nicotine's addictive properties. Furthermore, recent evidence that vaporiser use is a risk factor for future cigarette use ${ }^{14-18}$ suggests that vaporiser use can serve as an important marker for youth who are at elevated risk for future nicotine use.

A fourth implication is that a different rationale for the regulation of vaporiser devices will be required as compared to the 
regulation of vaporiser contents. The finding that most US youth do not vape nicotine makes it difficult to ban sales of vaporisers to youth on the grounds that all of them intrinsically deliver harmful substances to children in all circumstances, a primary rationale to ban the sale of cigarettes to youth. In the absence of an established body of evidence that links vaping any substance to impaired health, bans on sales of vaporisers to youth may need to draw on other rationales, such as the potential of vaporisers to desensitise youth to the dangers of tobacco smoking, and/or the argument that children are at high risk to unintentionally vape substances that will harm them.

In contrast, the rationale that children should be protected from harmful substances can be readily extended to the regulation of specific substances marketed for vaporisers. The fact that a substantial portion of youth are vaping nicotine, even if not the majority, underscores the importance of regulations aimed at clearly labelling the contents of these commercial materials and preventing children from access to the ones known to be harmful. Recently proposed 'deeming' rules by the US Food and Drug Administration ${ }^{19}$ provide a cornerstone for regulations along these lines.

It is important to note three limitations of this study. First, it is possible that youth may self-report that they are not using nicotine when, in fact, they are vaping nicotine but do not realise it. This may increase somewhat the estimates of nicotine use among the least experienced users who may not recognise the physiological symptoms associated with nicotine use. The most accurate knowledge of substances vaped is expected to be among the most experienced users, which in this study are the 12th-grade students who vaped six or more times in the last 30 days and presumably are more intentional in the substances they vape. The study's main conclusion that most youth who use vaporisers do not vape nicotine is bolstered by the fact that less than half of this experienced group reported vaping nicotine, a finding difficult to ascribe to inaccurate self-reports.

A second limitation is that the sample of frequent vapers who vaped six or more times in the past 30 days is not large enough to support in depth analysis. This small group is of considerable importance for theory and for policy. On the one hand, it may represent a new class of substance user who uses vaporisers exclusively, a class supported by preliminary evidence in a recent analysis of e-cigarette users in 12th grade. ${ }^{20}$ On the other hand, it may represent a standard, welldocumented class of polysubstance users who have simply extended their use of drugs to a new device. ${ }^{21-23}$ Furthermore, the heightened use of nicotine in this group warrants future analysis to examine whether their level of nicotine inhaled reaches that of their peers who use cigarettes. A third limitation is that the study lacks information on youth who have vaped multiple, different substances within the past 30 days. Some non-smoking youth who last vaped flavouring in the past 30 days may have also vaped nicotine earlier in the 30-day period, information not currently available in the data because the survey asks about only substance last vaped. Future MTF surveys will collect more detailed information on substances vaped, which will support an alternative measure of nicotine prevalence that takes into account this possibility of youth vaping multiple, different substances These measures will likely increase estimates of the percentage of youth who vape substances other than flavouring.

In conclusion, the majority of US youth who use vaporisers and e-cigarettes do not vape nicotine. This finding challenges many common assumptions and practices, and points to the need for vaporiser-specific research to assess and ultimately regulate the public health threat of vaporisers. Taking into account this finding now, while the field is young, will help ensure that future vaporiser science and regulations are built on a solid footing.

\section{What this paper adds}

- The use of vaporisers such as e-cigarettes by adolescents has grown exponentially in recent years, but little is known about what substances they are vaping.

- Using a nationally representative sample of adolescents we find that most of them (about $60 \%$ ) report that they vaped 'just flavouring' at last use. Less than a quarter reported vaping nicotine at last use.

- These results challenge the common assumption that most youth use vaporisers to vape nicotine.

Contributors LDJ is the principal investigator of the Monitoring the Future Study, and the other authors are all co-investigators. RM developed the paper plan, performed the data analysis and drafted the manuscript, assisted by MEP. All authors contributed to drafts of the manuscript.

Funding This study was supported by the National Institute on Drug Abuse, part of the National Institutes of Health, by grant number R01DA001411.

Competing interests None declared.

Ethics approval University of Michigan Institutional Review Board, approval number HUM00063656.

Provenance and peer review Not commissioned; externally peer reviewed.

Data sharing statement The data are drawn from a wider survey that examines trends in the use of more than 50 substances among adolescents. Each year a deidentified version of the previous year's data is made publicly available and can be downloaded for no charge at: http://www.icpsr.umich.edu/icpsrweb/NAHDAP/index. jsp.

\section{REFERENCES}

1 Johnston LD, O'Malley PM, Miech RA, et al. Monitoring the future national survey results on drug use: 1975-2015: overview of key findings on adolescent drug Use. Ann Arbor, MI: Institute for Social Research, The University of Michigan, 2016.

2 Corey C, Wang B, Johnson SE, et al. Notes from the field: electronic cigarette use among middle and high school students - United States, 2011-2012. Morb Mortal Wkly Rep 2013;62:729-30.

3 Miech RA, Johnston L, O'Malley PM, et al. E-cigarettes surpass tobacco cigarettes among teens. National Press Release, 2014. http://monitoringthefuture.org/ pressreleases/14cigpr_complete.pdf

4 Johnston LD, O'Malley PM, Bachman JG, et al. Monitoring the future national survey results on drug use, 1975-2012: Volume I, secondary school students. Ann Arbor, Ml: Institute for Social Research, The University of Michigan, 2013. http:/l monitoringthefuture.org/pubs/monographs/mtf-vol1_2012.pdf (accessed 1 Apr 2015).

5 Arrazola RA, Singh T, Corey CG, et al. Tobacco use among middle and high school students-United States, 2011-2014. MMWR Morb Mortal Wkly Rep 2015;64:381-5.

6 Hamilton HA, Ferrence R, Boak A, et al. Ever use of nicotine and nonnicotine electronic cigarettes among high school students in Ontario, Canada. Nicotine Tob Res 2015;17:1212-18.

7 Czoli C, Reid J, Rynard V, et al. E-cigarettes in Canada-Tobacco use in Canada: patterns and trends. Special Supplement. Waterloo, ON: Propel Centre for Population Health Impact, University of Waterloo, 2015.

8 Bachman JG, Johnston LD, O'Malley PM, et al. The Monitoring the Future Project after Four Decades: Design and Procedures. Occasional Paper \#82. 2015. http:/l monitoringthefuture.org/pubs/occpapers/mtf-occ82.pdf

9 O'Malley PM, Johnton LD, Bachman JG, et al. How substance use differs among American secondary schools. Prev Sci 2006;7:409-20.

10 Pampel FC. Diffusion, cohort change, and social patterns of smoking. Soc Sci Res 2005:34:117-39.

11 Miech RA. The formation of a socioeconomic health disparity: the case of cocaine use during the 1980s and 1990s. J Health Soc Behav 2008;49:352-66. 
12 Miech RA, Johnston L, O'Malley PM, et al. Monitoring the future National Survey results on drug use, 1975-2014: Volume I, secondary school students. Ann Arbor, MI: Institute for Social Research, The University of Michigan, 2015.

13 Amato MS, Boyle RG, Levy D. How to define e-cigarette prevalence? Finding clues in the use frequency distribution. Tob Control 2016;25(e1):e24-9.

14 Wills TA, Knight R, Sargent JD, et al. Longitudinal study of e-cigarette use and onset of cigarette smoking among high school students in Hawaii. Tob Control 2017;26:34-9.

15 Leventhal AM, Strong DR, Kirkpatrick MG, et al. Association of electronic cigarette use with initiation of combustible tobacco product smoking in early adolescence. JAMA 2015;314:700-7.

16 Primack BA, Soneji S, Stoolmiller M, et al. Progression to traditional cigarette smoking after electronic cigarette use among US adolescents and young adults. JAMA Pediatrics 2015;169:1018-23.

17 Bunnell RE, Agaku IT, Arrazola R, et al. Intentions to smoke cigarettes among never-smoking US middle and high school electronic cigarette users, National Youth Tobacco Survey, 2011-2013. Nicotine Tob Res 2015; 17:228-35.
18 Park JY, Seo DC, Lin HC. E-Cigarette Use and Intention to Initiate or Quit Smoking Among US Youths. Am J Public Health 2016;106:672-8.

19 Food and Drug Administration. Deeming tobacco products to be subject to the federal food, drug, and cosmetic act, as amended by the family smoking prevention and tobacco control act; restrictions on the sale and distribution of tobacco products and required warning statements for tobacco products. Final rule. Fed Regist 2016;81:28974-9106.

20 Miech RA, O'Malley PM, Johnston L, et al. E-Cigarettes and the Drug Use Patterns of Adolescents. Nicotine \& Tobacco Research 2016;185:674-9.

21 Gilreath TD, Astor RA, Estrada JN, et al. Substance use among adolescents in California: a latent class analysis. Subst Use Misuse 2013:49:116-23.

22 Conway KP, Vullo GC, Nichter B, et al. Prevalence and patterns of polysubstance use in a nationally representative sample of 10th graders in the United States. J Adolescent Health 2013;52:716-23.

23 Dierker LC, Vesel F, Sledjeski EM, et al. Testing the dual pathway hypothesis to substance use in adolescence and young adulthood. Drug Alcohol Depend 2007;87:83-93. 